\title{
Tolerância à dessecação em sementes de Bunchosia armenica (Cav.) DC.
}

\section{Desiccation tolerance of seeds of Bunchosia armenica (Cav.) DC.}

\author{
Kelina Bernardo Silva ${ }^{1 *}$; Edna Ursulino Alves ${ }^{2}$; \\ Riselane de Lucena Alcântara Bruno²; Edson de Almeida Cardoso ${ }^{3}$
}

\begin{abstract}
Resumo
As sementes têm comportamentos diferenciados quanto à tolerância à perda de umidade. Com o objetivo de determinar a tolerância à dessecação em sementes de Bunchosia armenica (Cav.) DC. (ameixa-dopará) foi coletado um lote de frutos desta espécie no município de Areia-PB. Após o despolpamento manual as sementes foram expostas para a secagem, sobre papel toalha, em condições de laboratório $\left(22{ }^{\circ} \mathrm{C}\right.$ e $85 \%$ UR) e casa de vegetação $\left(24^{\circ} \mathrm{C}\right.$ e $80 \%$ UR). Os tratamentos consistiram na amostragem para a determinação do teor de água e testes de emergência de plântulas no início do experimento e após $24,48,72,96$ e 120 horas. O teor de água foi avaliado pelo método da estufa a $105 \pm 3^{\circ} \mathrm{C}$ por 24 horas utilizando-se quatro repetições de 10 sementes para cada tratamento. $O$ teste de emergência de plântulas foi conduzido em casa de vegetação, com quatro repetições de 25 sementes. A contagem de plântulas emergidas foi realizada a cada dois dias, por um período de 35 dias e calculado o IVE, comprimento e a massa seca das plântulas. A secagem das sementes de $B$. armenica, em ambos os ambientes é viável por até 24 horas; Após 24 horas de secagem o teor de água das sementes é reduzido de 62,6\% para 57\%, sendo este considerado o nível crítico para a dessecação de sementes de ameixa-do-pará em ambos ambientes; Sementes de ameixa-do-pará são dispersas com teor de água muito elevado, e uma pequena redução neste valor compromete sua qualidade fisiológica, permitindo caracterizar as sementes desta espécie como recalcitrantes.
\end{abstract}

Palavras-chave: Secagem, ameixa-do-pará, vigor, frutífera exótica

\begin{abstract}
The seeds have different behaviors and tolerance to moisture loss. In order to determine desiccation tolerance in seeds of Bunchosia armenia (Cav.) DC. (Ameixa-do-Pará) was collected a lot of fruits of this species in Areia-PB. After the manual pulping the seeds were exposed to dry on paper towel, under laboratory conditions $\left(22^{\circ} \mathrm{C}\right.$ and $\left.85 \% \mathrm{RH}\right)$ and greenhouse $\left(24^{\circ} \mathrm{C}\right.$ and $\left.80 \% \mathrm{RH}\right)$. Treatments consisted of sampling for the determination of water content and seedling emergence tests at baseline and after $24,48,72,96$ and 120 hours. The water content was measured by the oven method at $105 \pm 3^{\circ} \mathrm{C}$ for 24 hours using four replicates of 10 seeds for each treatment. The seedling emergence test was conducted in a greenhouse with four replications of 25 seeds. The count of emergence has beenheld every two days, for a period of $35^{\text {th }}$ day and calculated the IVE, length and dry mass of seedlings. The drying of the seeds of B.armenica, in both environments is viable for up to 24 hours; After 24 hours of drying the water content of seeds is reduced from $62.6 \%$ to $57 \%$, a level considered critical to the desiccation of the seeds of Ameixa-do-Pará in both environments; Ameixa-do-Pará seeds nuts are dispersed with very high water content, and small reduction in physiological quality compromises their value, allowing the seeds to characterize this species as recalcitrant.
\end{abstract}

Key words: Seed, ameixa-do-pará, vigor, frutífera exótica

\footnotetext{
1 Eng $^{\mathrm{a}}$ Agr $^{\mathrm{a}}$, Dr $^{\mathrm{a}}$ em Agronomia, Bolsista CAPES, Depto. de Fitotecnia, CCA, Universidade Federal da Paraíba, UFPB, Areia, PB. E-mail: kelinabernardo@yahoo.com.br

2 Prof $^{a}$. Adjunta do Dept ${ }^{\circ}$. de Fitotecnia, CCA, UFPB, Areia, PB. E-mail: ednaursulino@cca.ufpb.br; lane@yahoo.com.br

3 Mestre em Agronomia Dept ${ }^{\circ}$. de Fitotecnia, CCA,UFPB, Areia, PB. E-mail: edsonagro@hotmail.com

Autor para correspondência
} 
A ameixa-do-pará (Bunchosia armenica (Cav.) DC.) é uma frutífera exótica cultivada no país há muito tempo, porém apenas em pomares domésticos. É originária de vários países andinos em altitudes de 1500 a $2400 \mathrm{~m}$, cujo porte é uma arvoreta perenifólia, de $2-5 \mathrm{~m}$ de altura, folhas simples, cartáceas, pubescentes quando novas, de 10-17 cm de comprimento, flores andróginas e levemente perfumadas, formadas principalmente na primavera e dispostas em racemos axilares de até $10 \mathrm{~cm}$ de comprimento. Os frutos são do tipo drupa que amadurecem durante o verão, com endocarpo (polpa) fino e carnoso, de sabor adocicado, contendo uma única semente que compõe mais de $90 \%$ do volume do fruto, os quais são consumidos in natura e como doces, porém não muito apreciados (LORENZI, et al., 2006).

Quanto ao potencial de armazenamento, as sementes em geral são classificadas em dois grupos distintos: ortodoxas e recalcitrantes. As ortodoxas mantêm-se viáveis após a secagem até o teor de água de até $5 \%$ e permanecem viáveis por longos períodos sob baixas temperaturas, enquanto as recalcitrantes perdem rapidamente a viabilidade se forem secadas a teores de água muito baixos (ROBERTS, 1973). E ainda há as sementes que apresentam comportamento intermediário entre os citados, tolerando a dessecação entre 7 e $10 \%$ de teor de água e não toleram baixas temperaturas durante períodos de tempo prolongado, conforme verificado por Carvalho, Silva e Davide (2006) em várias espécies florestais.

Existem vários métodos de secagem de semente, no entanto, todos visam à obtenção de sementes que, quando semeadas, germinem e originem plântulas vigorosas (CARVALHO; NAKAGAWA, 2000). Na secagem natural as sementes são secadas essencialmente pela ação do calor e do vento, sem o uso de equipamento mecânico e/ou eletroeletrônico; este tipo de secagem é mais lento e de baixo custo, quando comparado com o método artificial, sujeita, portanto, às modificações climáticas, razão pela qual é utilizada principalmente nas pequenas propriedades (CARVALHO, 2005).

O processo de secagem ocorre mediante duas fases, sendo a primeira, a transferência de água da superfície da semente para o ar que a circunda e, a segunda o movimento da água do interior da semente para a superfície (CARVALHO; NAKAGAWA, 2000). A secagem das sementes, além de contribuir para a preservação da qualidade fisiológica durante o armazenamento, possibilita a antecipação da colheita (GARCIA et al., 2004). Em sementes ortodoxas, a redução do teor de água retarda os processos fisiológicos como a respiração e o consumo das reservas nutritivas armazenadas em seus tecidos de reserva, prevenindo a proliferação de fungos e bactérias, enquanto para as sementes recalcitrantes ou intermediárias, a secagem pode levar a morte do embrião. Nas sementes florestais, a secagem é feita por método natural e artificial, o primeiro refere-se à exposição dos frutos e/ou sementes a ação dos ventos e energia solar, enquanto o outro ocorre pela movimentação da massa de ar de secagem por meio de equipamentos especiais (MEDEIROS; EIRA, 2006).

Assim, este trabalho foi desenvolvido com o objetivo de avaliar a germinação e o vigor das sementes de Bunchosia armenica (Cav.) DC. em função do período e do ambiente de secagem.

Os frutos maduros de $B$. armenica, de coloração avermelhada e completamente maduros foram colhidos diretamente em indivíduos localizados no município de Areia, em março de 2009. Depois de colhidos foram transportados em embalagem de polietileno até o Laboratório de Análise de Sementes da Universidade Federal da Paraíba, onde foram despolpados manualmente mediante maceração manual e lavagem em água corrente. Após a lavagem, as sementes foram expostas para a secagem, em condições de laboratório $\left(22{ }^{\circ} \mathrm{C}\right.$ e $85 \%$ UR) e casa de vegetação $\left(24{ }^{\circ} \mathrm{C}\right.$ e $80 \%$ UR).

Os tratamentos consistiram na secagem das sementes em casa de vegetação e condições 
ambientais de laboratório pelos períodos de 0 (sem secagem), 24, 48, 72, 96 e 120 horas. Para se proceder a secagem as sementes foram espalhadas em camada uniforme sobre papel toalha, sem incidência de luz.

As sementes foram submetidas a testes visando avaliar a sua qualidade fisiológica.

Umidade - a umidade foi determinada, antes e após cada período de secagem utilizando-se quatro sub-amostras de 10 sementes para cada tratamento, pelo método da estufa a $105 \pm 3{ }^{\circ} \mathrm{C}$ por 24 horas, seguindo as recomendações de Brasil (2009), com exceção do tamanho da amostra e número de repetições.

Teste de emergência de plântulas - foi realizado em ambiente protegido, (com temperatura média de $24{ }^{\circ} \mathrm{C}$ e umidade relativa média de $80 \%$ durante o período de avaliação) com quatro repetições de 25 sementes, semeadas em bandejas plásticas com dimensões de 41 x 36 x 7,6 cm de comprimento, largura e profundidade, respectivamente, contendo areia lavada e esterilizada em autoclave como substrato, cuja manutenção da umidade foi por meio de irrigações diárias. A contagem do número de plântulas emergidas foi realizada quando a parte área apresentou-se acima do solo. Os resultados foram expressos em porcentagem.

Índice de velocidade de emergência (IVE) este teste foi conduzido juntamente com o teste de emergência, com contagens realizadas a cada dois dias, por um período de 35 dias após a instalação do teste, quando se obteve o número máximo de plântulas emergidas. $O$ índice foi calculado utilizando-se a fórmula proposta por Maguire (1962).

\section{Comprimento e massa seca de plântulas - no} final do teste de emergência, as plântulas normais foram medidas com o auxílio de uma régua graduada em centímetros, sendo os resultados expressos em centímetros por plântula. Logo após as medições, as plântulas normais tiveram seus cotilédones removidos e essas foram postas em sacos de papel e levadas a estufa regulada a $65^{\circ} \mathrm{C}$ até massa constante. Decorrido este período, as mesmas foram pesadas em balança analítica com precisão de $0,001 \mathrm{~g}$.

O delineamento experimental utilizado foi inteiramente ao acaso em quatro repetições e os dados obtidos foram submetidos à análise de variância e de regressão polinomial, verificando-se os efeitos linear, quadrático e cúbico das variáveis, em função dos tratamentos, sendo selecionado para expressar o comportamento de cada variável, o modelo significativo de maior ordem. O teor de água inicial das sementes foi de $62,6 \%$, reduzindo para 43,3 e $32,1 \%$ após 120 horas de secagem em ambiente de laboratório e casa de vegetação, respectivamente (Figura 1). O comportamento da secagem ao longo das 120 horas foi linear, indicando uma perda uniforme de água. Como se pode observar, no momento da dispersão, as sementes apresentavam alto teor de água, o que é característico de sementes recalcitrantes. Ao contrário de sementes ortodoxas, as sementes recalcitrantes não passam por um dessecamento acentuado durante a maturação e/ou, antecedendo a dispersão (ROBERTS; KING, 1980).

Nesse sentido, quando as sementes recalcitrantes são desidratadas após a coleta, ocorre a perda gradual da viabilidade com o dessecamento, passando por um ponto crítico até atingir o teor de água chamado letal. Comportamento semelhante foi observado por Andrade, Schorn e Nogueira (2005) em sementes de Archantophoenix alexandrae Wendl and Drude, onde observaram que a partir das 78 horas de secagem as sementes estavam com $24,84 \%$ de umidade considerando-se como teor de água letal. Da mesma forma, Nazário, Ferreira e Rebouças (2008) em sementes de Cynometra bauhiniifolia Benthan verificaram que o teor de água crítico situou-se entre 46,6 e $41,4 \%$, enquanto o teor de água letal ficou entre 28,2 e $23,9 \%$, o que são características típicas de sementes recalcitrantes. 
Figura 1. Teor de água (\%) das sementes de Bunchosia armenica, em função da secagem em laboratório (Lab) e casa de vegetação $(\mathrm{CV})$.

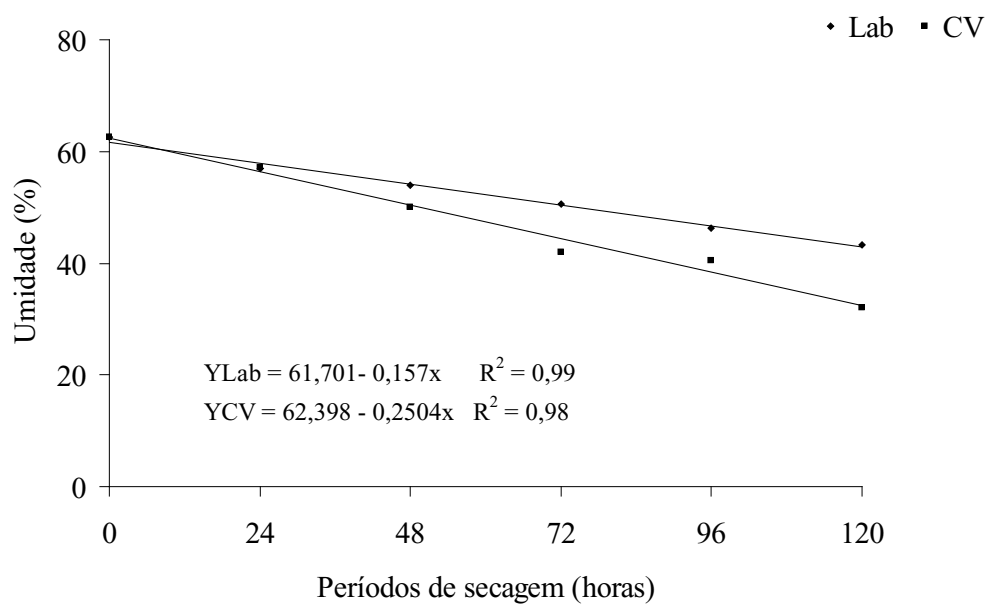

Fonte: Elaboração dos autores.

A emergência de plântulas foi influenciada água, tendo alcançado emergência inicial de $72 \%$ pela dessecação das sementes, decrescendo (0 horas) e, ao final das 120 horas, de 18 e $14 \%$, progressivamente do período de zero a120 horas, com secagem em laboratório e casa de vegetação, coincidindo com a redução progressiva do teor de respectivamente (Figura 2).

Figura 2. Emergência de plântulas de Bunchosia armenica em função da secagem em laboratório (Lab) e casa de vegetação $(\mathrm{CV})$.

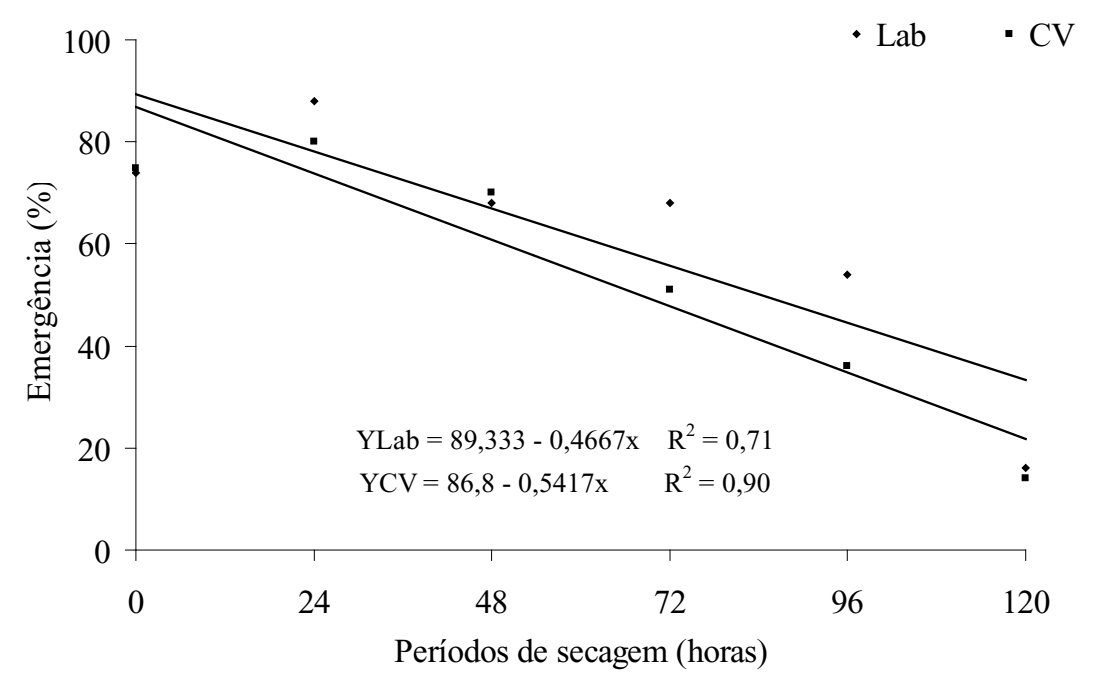

Fonte: Elaboração dos autores. 
A exposição das sementes à dessecação demonstrou tolerância até 24 horas, quando foi atingido o teor de água de 57 e $57,1 \%$, em sementes postas para secar em laboratório e casa de vegetação, respectivamente. A partir desse período a porcentagem de emergência foi afetada significativamente. Esse teor de água pode ser considerado o nível crítico, pois Barbedo e Marcos Filho (1998) consideram este ponto como sendo aquele abaixo do qual a semente não suporta a secagem. Este teor de água crítico seria atingido após a perda de toda a água celular livre, e em diversos trabalhos e espécies pesquisadas foram obtidos valores de 15 a $38 \%$, mostrando que esta característica é muito variável de espécie para espécie e mesmo de indivíduo para indivíduo.
O comportamento ortodoxo ou recalcitrante em sementes, segundo Barbedo e Bilia (1998) pode ser originado de mecanismos de escape de destruição celular durante a perda de água. Quando células não tolerantes à dessecação são desidratadas, algumas consequências são observadas, a exemplo de solutos que podem ficar mais concentrados, aumentando as reações químicas destrutivas; alguns solutos podem cristalizar, modificando a resistência iônica e o pH da solução intracelular; inicia-se a desnaturação das proteínas e a ruptura das membranas celulares.

Observa-se na Figura 3 que o índice de velocidade de emergência reduziu linearmente, até alcançar valores de 0,16 e 0,12 , após 120 horas de secagem das sementes em ambiente de laboratório e casa de vegetação, respectivamente.

Figura 3. Índice de velocidade de emergência (IVE) de plântulas de Bunchosia armenica, em função da secagem das sementes em laboratório (Lab) e casa de vegetação (CV).

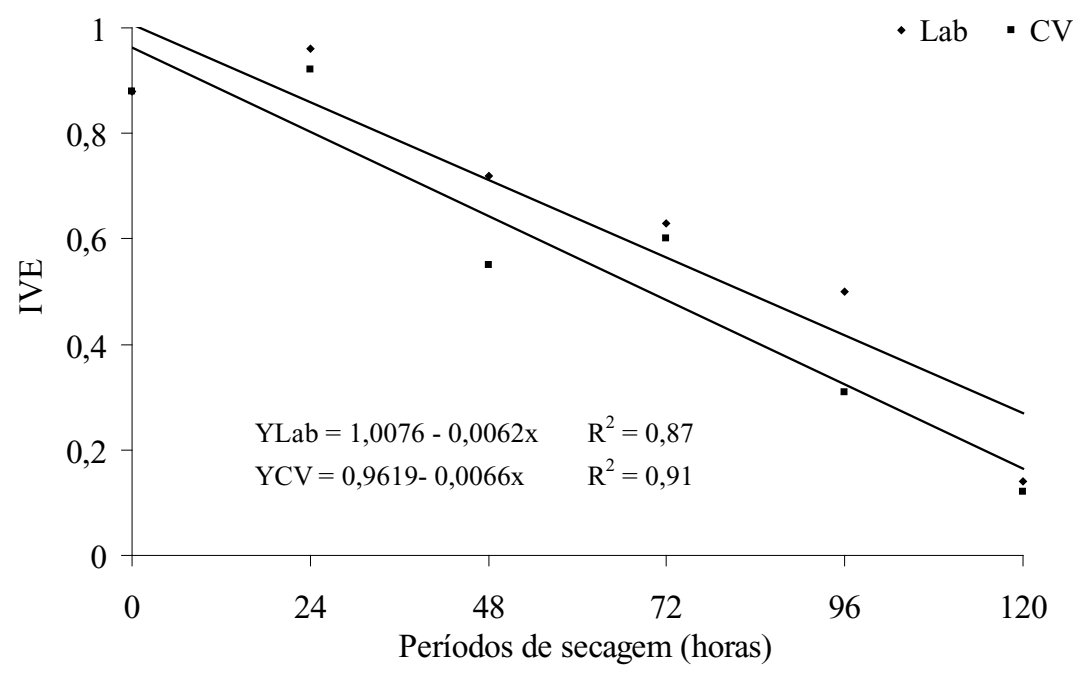

Fonte: Elaboração dos autores.

A redução do teor de água, de $46 \%$ para $40 \%$, afetou negativamente a qualidade fisiológicadas sementes armazenadas de camu-camu (FERREIRA; GENTIL, 2003). Com isso, ocorreu a redução da porcentagem e da velocidade de emergência, da altura, do diâmetro do colo, do número de folhas e da massa seca das plântulas, além do aumento do tempo médio de emergência das plântulas. Em trabalho paralelo, realizado com sementes da mesma espécie e procedência que as utilizadas no trabalho anterior, Gentil e Ferreira (2000) também verificaram os efeitos prejudiciais do decréscimo do teor de água, de $46 \%$ para $37 \%$, sobre a qualidade fisiológica das sementes, sugerindo que o teor de 
água crítico estivesse situado entre esses valores. Entretanto, considerando que foram observados danos provocados pela dessecação às sementes com $40 \%$ de umidade, é mais provável que o teor de água de segurança e o teor de água crítico estejam localizados entre 46 e $40 \%$ de umidade.

Trabalhando com Genipa americana $L$. (jenipapo), Oliveira et al. (2011) observaram que as sementes podem ser secas em ambiente telado $\left(33^{\circ} \mathrm{C}\right.$ e 70\% UR) durante 24 horas ou em laboratório $\left(28^{\circ} \mathrm{C}\right.$ e $\left.75 \%\right)$ por até 48 horas sem comprometer a qualidade fisiológica das mesmas. De modo geral, o maior comprimento e conteúdo de massa seca de plântulas foram obtidos com as sementes oriundas de dessecação por 24 horas (Figuras 4 e 5), sendo possível observar que as plântulas de ameixa-dopará não toleraram a dessecação por um período maior que 24 horas, diminuindo o vigor após esse tempo.

Figura 4. Comprimento de plântulas (cm) de Bunchosia armenica em função da secagem das sementes em laboratório (Lab) e casa de vegetação (CV).

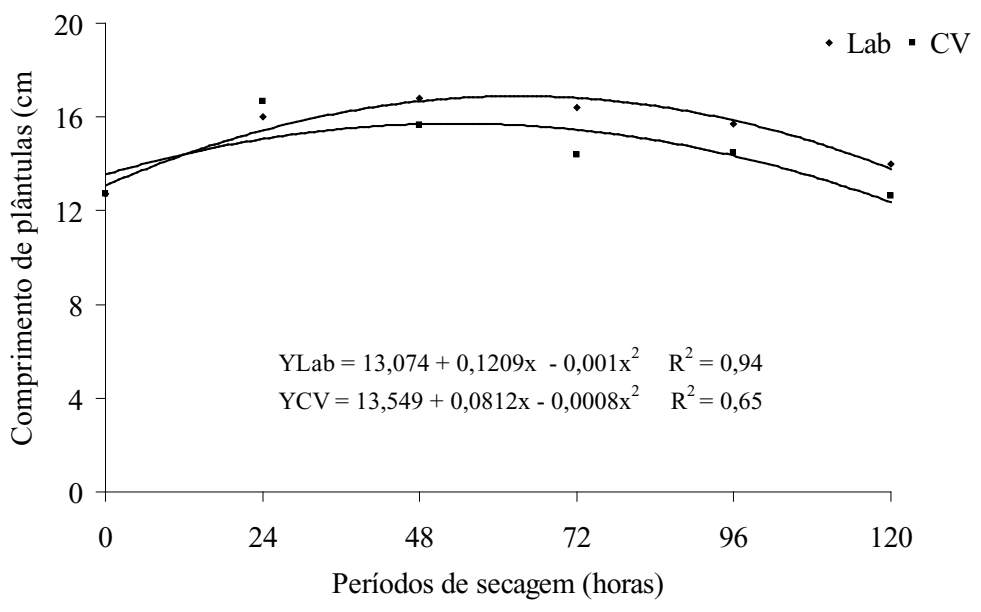

Fonte: Elaboração dos autores.

Figura 5. Massa seca de plântulas (g) Bunchosia armenica em função da secagem das sementes em laboratório (Lab) e casa de vegetação (CV).

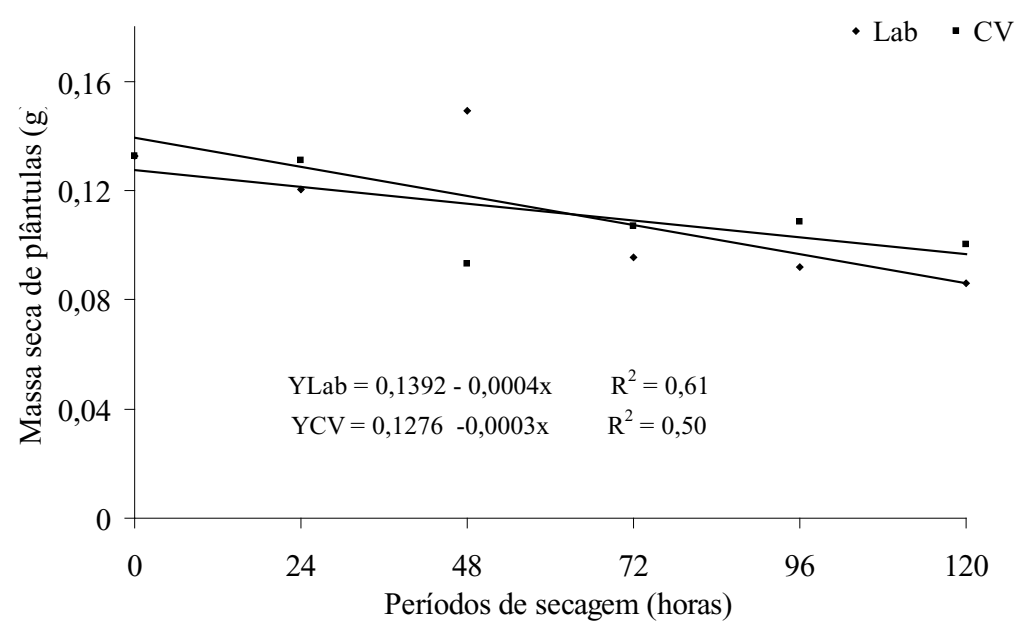

Fonte: Elaboração dos autores. 
São duas as principais causas da perda de viabilidade das sementes com a desidratação: conseqüência de metabolismo desequilibrado durante a desidratação e dano por desidratação quando a água é essencial para a integridade de estruturas intracelulares (BERJAK; PAMMENTER, 2003).

A secagem das sementes de Bunchosia armenica (Cav.) DC. (ameixa-do-pará), em ambos os ambientes é viável por até 24 horas; Após 24 horas de secagem o teor de água das sementes é reduzido de $62,6 \%$ para $57 \%$, sendo este considerado o nível crítico para a dessecação de sementes de ameixa-dopará em ambos ambientes; Sementes de ameixa-dopará são dispersas com teor de água muito elevado, e uma pequena redução neste valor compromete sua qualidade fisiológica, permitindo caracterizar as sementes desta espécie como recalcitrantes.

\section{Referências}

ANDRADE, R. R.; SCHORN, L. A.; NOGUEIRA, A. A. Tolerância à dessecação em sementes de Archantophoenix alexandrae Wendl. and Drude (palmeira real australiana). Ambiência, Guarapuava, v. 1, n. 2, p. 279-288, 2005.

BARBEDO, C. J.; MARCOS FILHO, J. Tolerância à dessecação em sementes. Acta Botânica Brasilica, São Paulo, v. 12, n. 2, p. 145-164, 1998.

BARBEDO, C. J.; BILIA, D. A. C. Evolution of research on recalcitrant seeds. Scientia Agrícola, Piracicaba, v. 55, p. 121-125, 1998. Especial.

BERJAK, P.; PAMMENTER, N. W. Chapter 4: orthodox and recalcitrant seeds. In: USDAForest service's/ reforestation, nurseries, e genetics resources. Tropical Tree Seed Manual, New York, v. 4, n. 1, p. 137-147, 2003.

BRASIL, Ministério da Agricultura e da Reforma Agrária. Regras para análise de sementes. Secretaria de Defesa Agropecuária. Brasília: MAPA/ACS, 2009, 399 p.

CARVAlHO, L. R.; SILVA, E. A. A.; DAVIDE, A. C. Classificação de sementes florestais quanto ao comportamento no armazenamento. Revista Brasileira de Sementes, Pelotas, v. 28, n. 2, p. 15-25, 2006.
CARVALHO, N. M. A secagem de sementes. 2. ed. Jaboticabal: FUNEP, 2005. 184 p.

CARVALHO, N. M.; NAKAGAWA, J. Sementes: ciência, tecnologia e produção. 4. ed. Jaboticabal: FUNEP, 2000. $588 \mathrm{p}$.

FERREIRA, S. A. N.; GENTIL, D. F. O. Armazenamento de sementes de camu-camu (Myrciaria dubia) com diferentes graus de umidade e temperaturas. Revista Brasileira de Fruticultura, Jaboticabal, v. 25, n. 3, p. 440-442, 2003.

GARCIA, D. C.; BARROS, A. C. S. A.; PESKE, S. T.; MENEZES, N. L. A secagem de sementes. Ciência Rural, Santa Maria, v. 34, n. 2, p. 603-608, 2004.

GENTIL, D. F. O.; FERREIRA, S. A. N. Tolerância à dessecação e viabilidade de sementes de camu-camu. Revista Brasileira de Fruticultura, Jaboticabal, v. 22, n. 2, p. 264-267, 2000.

LORENZI, H.; BACHER, L.; LACERDA, M.; SARTONI, S. Frutas brasileiras e exóticas cultivadas (de consumo in natura). São Paulo: Instituto Plantarum de Estudos da Flora, 2006, 640 p.

MAGUIRE, J. D. Speed of germination-aid selection and evalution for seedling emergence and vigor. Crop Science, Madison, v. 2, n. 1, p. 176-7, 1962.

MEDEIROS, A. C. S.; EIRA, M. T. S. Comportamento fisiológico, secagem e armazenamento de sementes florestais nativas. Colombo: EMBRAPA, 2006. 13 p. (Circular técnica, 127).

NAZÁRIO, P.; FERREIRA, S. A. N.; REBOUÇAS, E. R. Germinação de sementes de Cynometra bauhiniifolia Benthan (jutairana) em função do dessecamento e da manutenção sob condição úmida. Acta Amazonica, Manaus, v. 38, n. 3, p. 439-444, 2008.

OLIVEIRA, L. M.; SILVA, E. O.; BRUNO, R. L. A.; ALVES, E. U. Períodos e ambientes de secagem na qualidade de sementes de Genipa americana L. Semina: Ciências Agrárias, Londrina, v. 32, n. 2, p. 495-502, 2011.

ROBERTS, E. H. Predicting the storage life of seeds. Seed Science \& Technology, London, v. 1, n. 1, p. 499514, 1973.

ROBERTS, E. H.; KING, M. W. The characteristics of recalcitrant seeds. In: CHIN, H. F.; ROBERTS, E. H. Recalcitrant crop seeds. Kuala Lumpur: Tropical Press SDN/BHD, 1980. p. 1-5. 
